\title{
The architectural investigation of the historical bathrooms and the analysis of the interior space, the case study: the reviving and the repairing of bazaar bathroom (Ganbar Amu bathroom) in Shabestar
}

Investigación arquitectónica de los baños históricos y el análisis del espacio interior, estudio de caso: la reactivación y la reparación del baño Bazar (baño Gambar Amu) en Shabestar

Author:

Mohammad Dabdabeh ${ }^{1, *}$

Omid Shaterivaighan ${ }^{2}$

Vahid Kahyazadeh ${ }^{3}$

\section{SCIENTIFIC RESEARCH}

How to cite this paper:

Dabdabeh. M., Shaterivaighan. O., Kahyazadeh. Vahid. The architectural investigation of the historical bathrooms and the analysis of the interior space, the case study: the reviving and the repairing of bazaar bathroom (Ganbar Amu bathroom) in Shabestar. Shabestar, Iran.Innovaciencia. 2019; 7(2): 1-14.

DOI:http://dx.doi.org/10.15649/2346075X.759

\section{ABSTRACT}

The very ancient bathrooms of Iran are very popular, beautiful, valuable and historical. The aspects of social, cultural, sanitational and medical have been taken into account in these bathrooms. The people of Iran have had a long history about bathing and through the appearance of Islam it can be said that the interior architecture of the bathrooms were like each other in Iran. The present study is about the very ancient historical bathroom of Ganbar Amu in Shabestar which dates back to the Qajar era. At present the mentioned bathroom is being repaired so that its beauty and value can be preserved. This is a descriptive-analytical study and the main goal of the study is to introduce the historical spaces of the ancient bathrooms and presenting a restoration polanning for the historical bathrooms like Ganbar Amu bathroom in Shabestar.

Reception date:

Received: 15 January 2019

Accepted: 28 April 2019

Published: 25 October 2019

Keywords:

Bathroom, Repair, Architecture, Interior Architecture, Shabestar.

1* Young Researchers and Elite Club, Shabestar Branch, Islamic Azad University, Shabestar, Iran

Email: mohammad.dabdabeh74@gmail.com

2 Department of Architecture, Shabestar Branch, Islamic Azad University, Shabestar, Iran

3 Department of Architecture, Tabriz Branch, Islamic Azad University, Tabriz, Iran 


\section{INTRODUCTION}

The architecture of the Qajar period in our bathrooms, mosques, schools, bridges and other main buildings is the continuation of the architecture of the foretime eras especially the safavids ear. Iran's ancient historical bathrooms like other valuable works have special patterns and architecture.

Planning, designing and the building the iranian bathtooms have a record of thousands of years and based on the archaeological excavations in perspolis it dates back to the era of achamenian. This process continued up to the islamic ear and with some changes reached to the era of the Qajar. Iranian bathrooms compared with the historical buildings almost had the same patterns and design and the climate had no such signinficant impact (Gobadian, 2012) ${ }^{[1]}$. Unfortunately bathrooms have always been in danger compared to the other buildings. Bathrooms have always had an old relationship with customs, cleaninig methods and religion.

This study aims to investigate bathing, bathrooms and the iranian culture in the Qajar era. Did the bathing, washing and the other clinical methods have special applications among the people or not? What was the design and the patterns of the bathrooms in the era of Qajar?

The following study is to answer all the abovementioned questions and in this rregard the researcher has tried to use and gather the information based on the different usefull books, information and outstanding libraries.

2. THE EFFECTS OF CULTURE SOCIETY IN THE HISTORICAL BATHROOMS OF IRAN

Bath and bathing can be considered as one of the social cultural dimention in the structure of the architectural building. Bathroom is an opportunity both for men and women to clean, make up as well as to wash themselves. One of the customs of the Qajar era was to use Henna. In those days building bathrooms near public places like mosques, bazaar was customary. Going to the public bathrooms was a good chance and opportunity to meet each other and to talk about different topics there.

\section{THE EFFECT OF HYGIENE AND THERAPY IN THE HISTORICAL BATHROOMS OF IRAN}

The architecture of Iran's historical bathrooms is healing because the main idea behind making these bathrooms is hygiene and therapy. Based on the different religions the main idea of washing and bathing is hygiene (Lotfi, Masjedi, 2013) ${ }^{[2]}$. Imam Mohammad Baqer (P.B.U.H.), says in an exemplum about the bathrooms that" The best medicine for you is bathing, bloodletting and dropping medicine in your nose" (Majlesi, 2005) ${ }^{[3]}$. The ancient bathrooms were very important interms of healing and most of the physicians had lots of findings about them. Bathrooms were not only the historical places but also places for the healing too (Fakhar Tehrani, 2000) ${ }^{[4]}$. 
4. ARCHITECTURE AND THE

ARCHITECTURE OF THE INTERIOR SPACES OF THE IRANIAN TRADITIONAL BATHROOMS

\subsection{Interior spaces}

- Portal: The very first part of coming and going in and out of the bathroom was the portal and it had other social applications too.

- Porch: It was a space after entering the bathroom and it was the second entrance and here the space was divided into several parts and had different shapes in different places.

- Corridor: Door way, the cooridor, the space of transferring and was built as having angles with different plannings (Pirnia, 1993) ${ }^{[5]}$.

- The Space of between in: The main space between Sarbineh and hothouse in the bathrooms which separated the hothouse and sarbineh in order to decrease the heat between them.

\subsection{Main spaces}

- Bineh / Sarbineh: The largest space of the bathroom and in this space there were the resting place and the dressing room which were used for talking or drinking coffee, tea, etc (Bulukbashi, 1995) [6].

- Hothouse: The main space of the bathroom used for cleaning and men or women cleaned and washed themselves with soap and washcloth.

- Khazineh: There was a small room for washing near the hothouse and people went there so that the half part of their whole body can not be seen and there they washed themselve.

- Pool: There was a vast space with a very lage pool full of cold water near the hothouse and it was very deep and used for swimming (Tabasi, 2011) [7].

\subsection{Service spaces}

- Atrium: A small space used for the master of the bathroom to sit on.

- Lavatory: A service space that its access was within the main door.

- Place of depilatory: A space for the people to remove their extra hair in their body or to use Henna for their body.

- The bathroom roof: It was used to hand wet wrapaounds of the bathroom.

\subsection{Facility spaces}

- Fire house: A place in the bathroom and furnace was in that place.

- Fuel warehouse: A space or place which was used to store and keep the fuel of the bathroom.

- Sewage: An open space for emptying the sewage in the open air (Tabasi, 2013) ${ }^{[8]}$.

- Gav ru: A place for draining water.

- Catwalk: A place under the floor to repel moisture and hot air as well as smoke of the fireplace. It also used to heat the floor of the bathroom.

\section{SHABESTAR}

The cities of Marand and Varzegan are in the northern part of Shabestar and its southern and eastern parts are covered by Tabriz and Osku and its western part is the city of Urmieh and west Azarbaijan. Shabestar is located in the $50 \mathrm{kms}$ west of Tabriz and TabrizUrmieh. Shabestar with 2629 square kms of breadth is 6.5 percent of the east Azarbaijan provience. It has eight cities, eight vills and 99 villages. Shabestar has 3 main districts of Sufiyan, cental and Anzab (Purrajabi, Allem, 2004) ${ }^{[9]}$. Also based on (Fig. 1), Shabestar aerial map on google earth. 


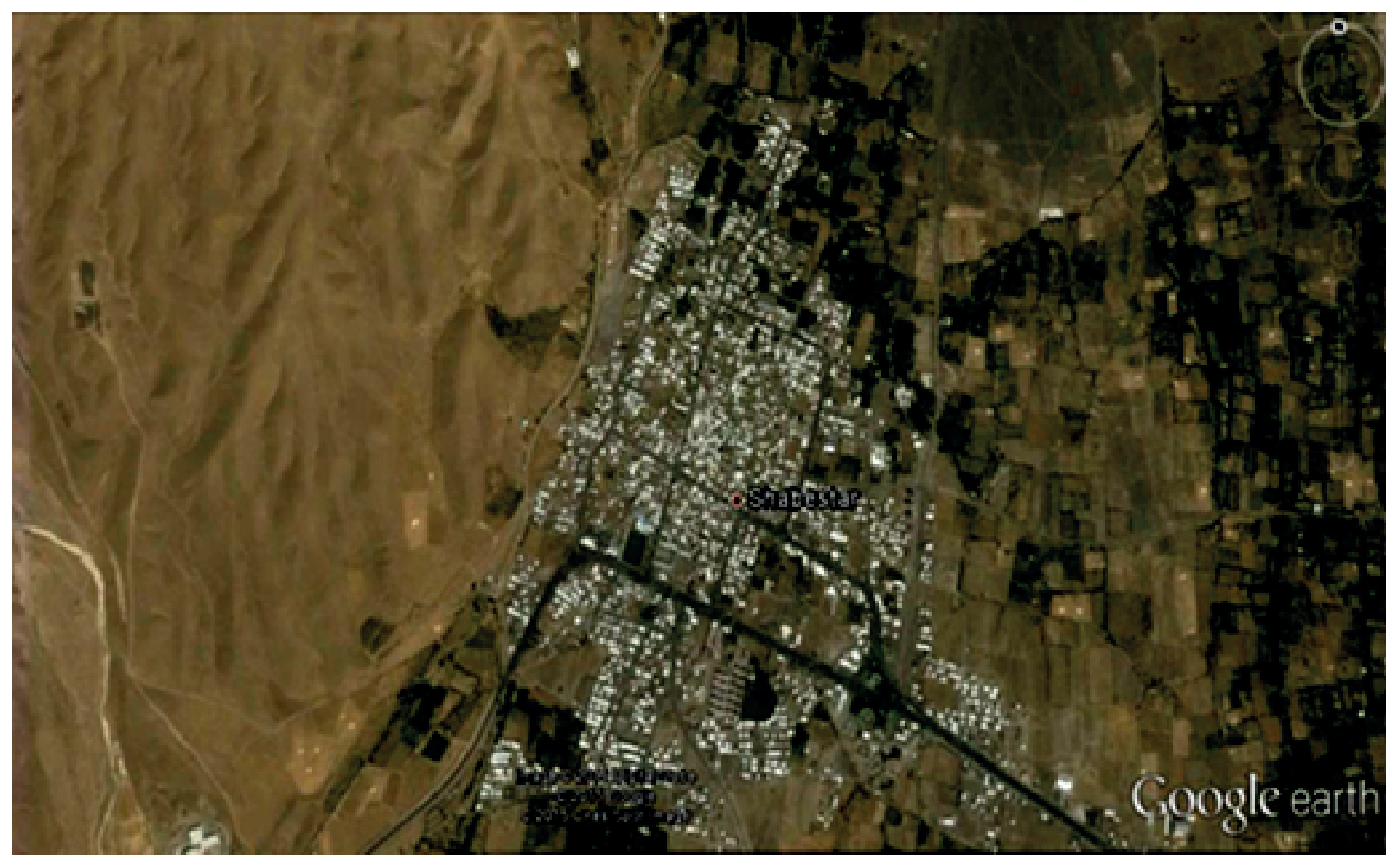

Fig. 1. Shabestar aerial map on google earth (Source: Writers)

\subsection{The status of climate in Shabestar}

Topography is one of the most important factors of creation and the climate chararcteristics of Shabestar. It is also the main factor in its diversity. The general altitude of the land varies form 1300 to $3155 \mathrm{~m}$. As a matter of fact such a difference in altitude alone would make a difference in the average annual temperature. The climatic characteristics of the solar radiation angle in other words, the latitude of the Shabestar city are 45, 41, 30 and 38 .

\subsection{The study area of the Bazaar Bathroom} (Ganbar Amu Bathroom) of Shabestar on the map of Shabestar

The study area of the Ganbar Amu Bathroom on the map of Iran, (fig. 2 ) based on (fig. 3). 


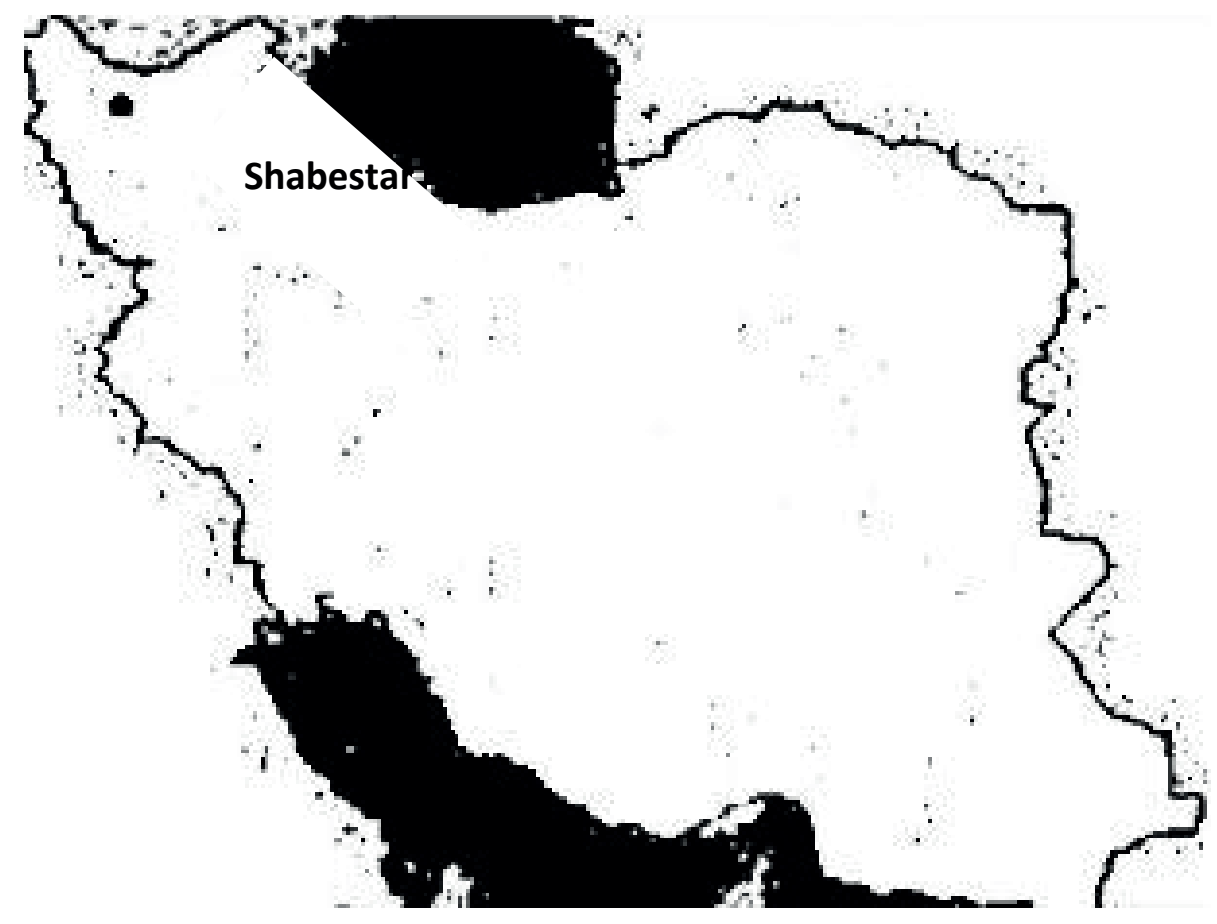

Fig. 2. Study Range on Iran Map (Source: Writers)

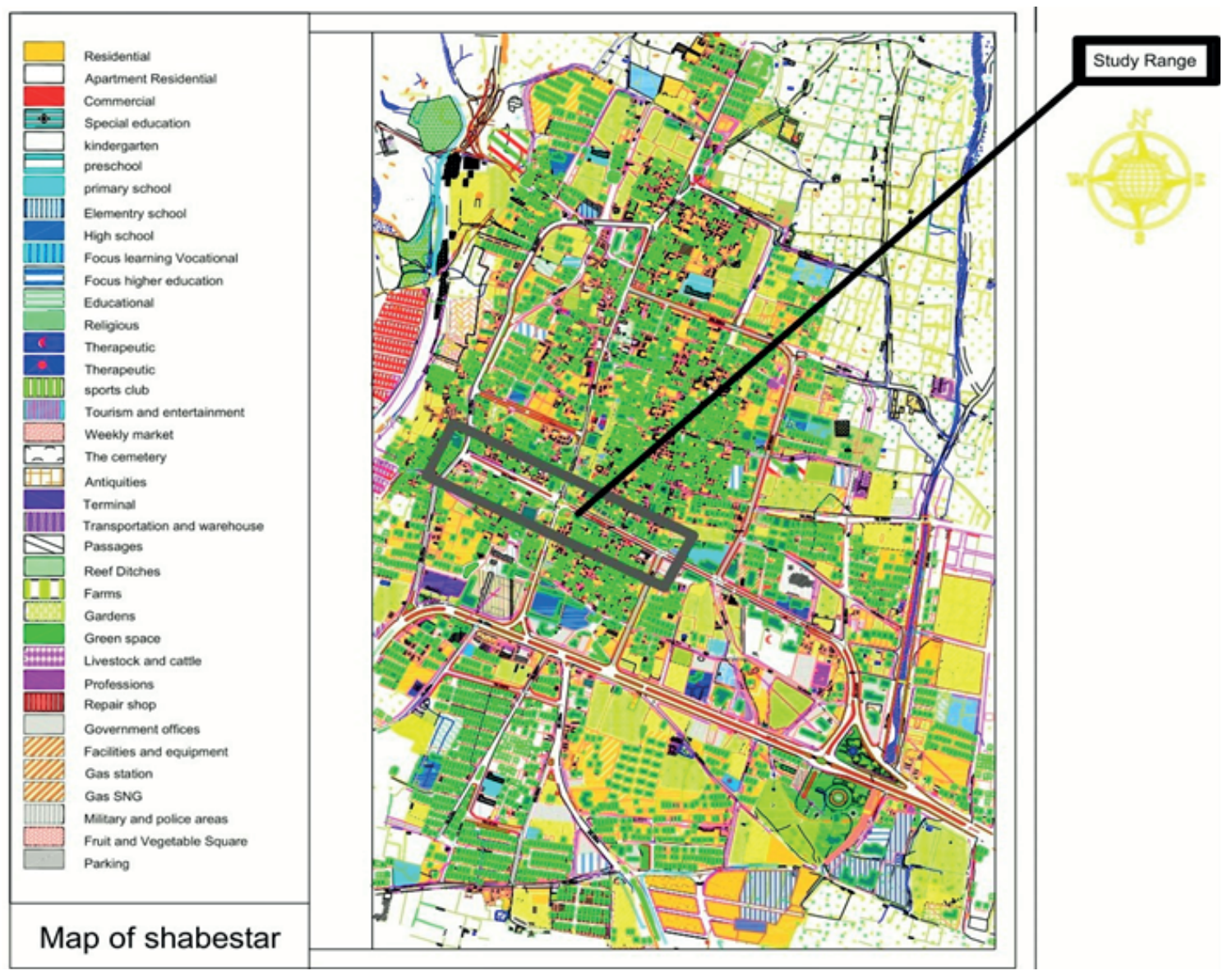

Fig. 3. The study area of the Bazaar Bathroom The (Ganbar Amu Bathroom( of Shabestar (Source: Writers) 


\section{THE BAZAAR MARKET (THE GANBAR AMU BATHROOM) IN SHABESTAR}

Country: Iran

Provincw: East Azarbaijan

City: Shabestar

Registration Number: 12450

Date of Registration: 2005/Aug/06

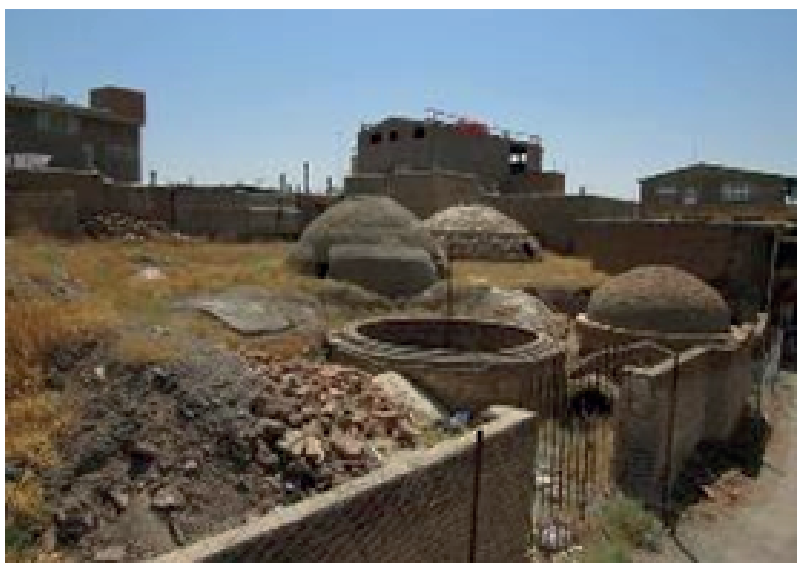

Fig. 4. The exterior view (Source: Wrirers)

\subsection{The ownership of the (Ganbar Amu Bath- room) in Shabestar}

At present the ownership of this bathroom belongs to four people.One of them is Abbas Melekmohammadi who had bought it from the late GAnbar Amu and the other three people are the heirs of the late Ganbar Amu. The late Ganbar Amu was the owner of this bathroom about 60 years ago.

6.2 The investigation of the architecture and the status of the (Ganbar Amu Bathroom) in Shabestar

From the time of the construction of this bathroom up to now the bathroom has its own sustainability and its main structure is upright but there are some damages to the parts of the building, for example

\section{Dating: Qajar era}

Primary Use: Bathroom

Address: Bath Alley, Shariati Ave, Sheikhmahmood Shabestari Bazaar, The central District, Shabestar, Iran

This bathroom is located in Shabestar in one of the most remarkable historical complex which dates back to the Qajar era (Figures 4 and 5).

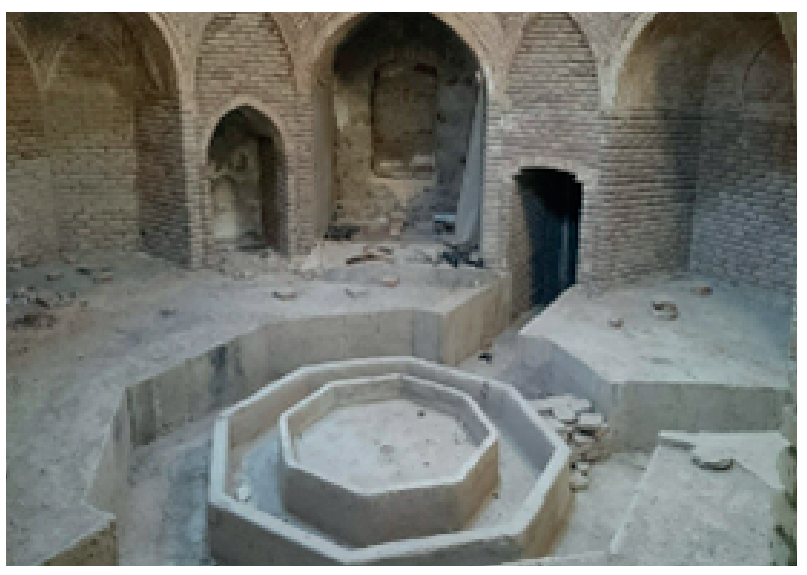

Fig. 5. The interior view (Source: Writers)

the eastern entrance ceiling has been badly destroyed and now there are just a few piles of wood. The signs of the destruction can also be seen on the domes of the building. The roof of the bathroom has also been damaged badly. The Khazineh (The very old part of the bathroom in the past), has also been completely damaged. From the western part of the city all the other buildings have been bought and destroyed because of the bathroom but the repairing of the bathroom have been a very difficult task. There are lots of problems for the people who live there and the other people who pass it have lots of difficulties because of the ruins of this bathroom. You can also see lots of trash and no one pays any attention to it. It can be said that the complete structure of the bathroom has been disappeared. 


\subsection{The plan of the historical bathroom of} (Ganbar Amu Bathroom) in Shabestar

Throughout iran, the general plan of the bathrooms was the same. The only difference was in the depth of the hot and cold climate regions (Srikhani, 2003) [10]. The Ganbar Amu bathroom due to the cold climate has more depth and is a perfect example of the architecture of the Qajar era (Fig. 6).

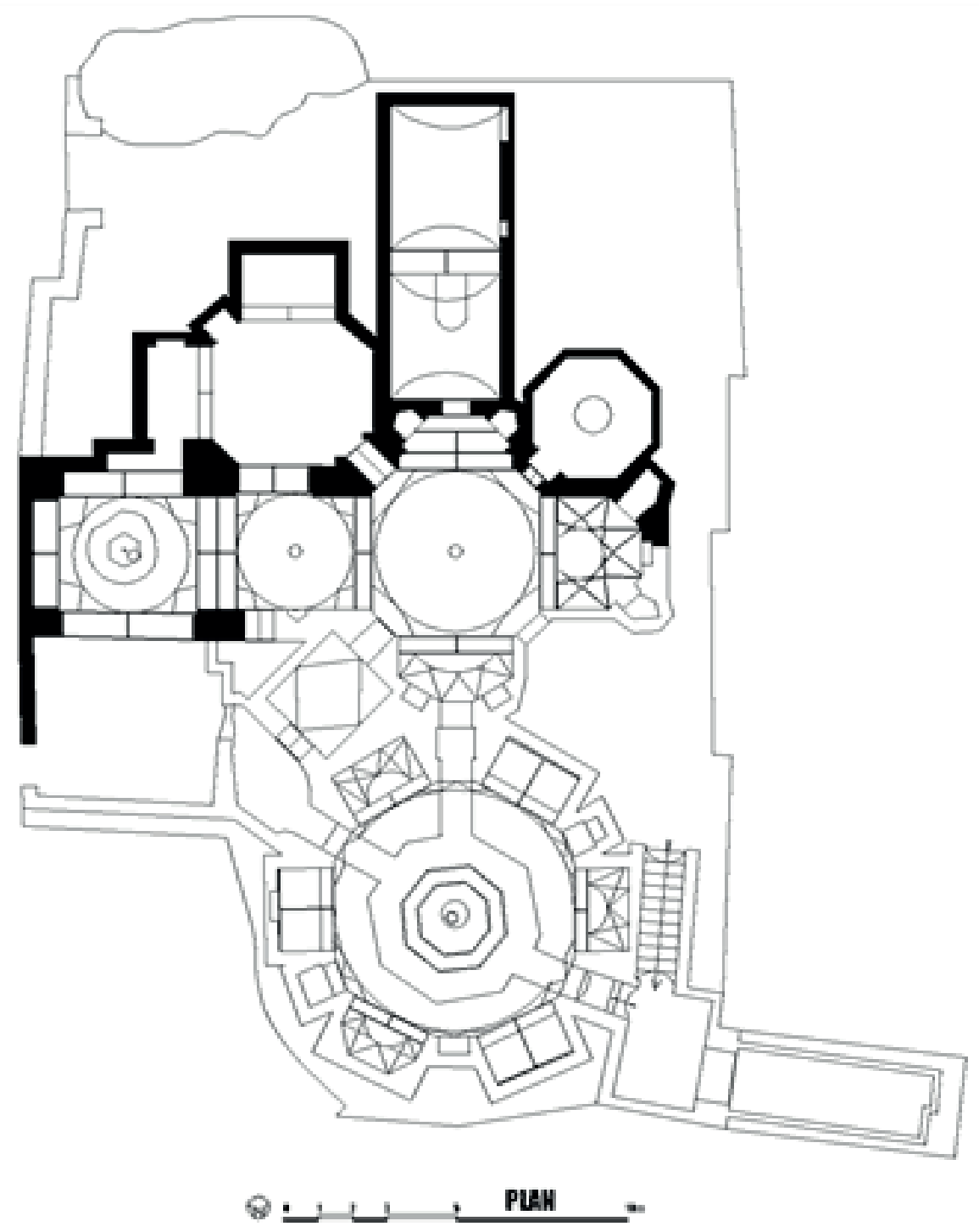

Fig. 6. The plan of the Bazaar Bathroom the of (Ganbar Amu Bathroom) (Source: Writers)

\section{4 (Ganbar Amu Bathroom) profile façade}

The main and the most elements of this bathroom are the protruding domes with remarkable architecture which have outstanding influence on the visitors. The interior view of the building is also very remarkable in the framework of the design which shows the perfect example of the Islamic-interior architecture (fig. 7). 


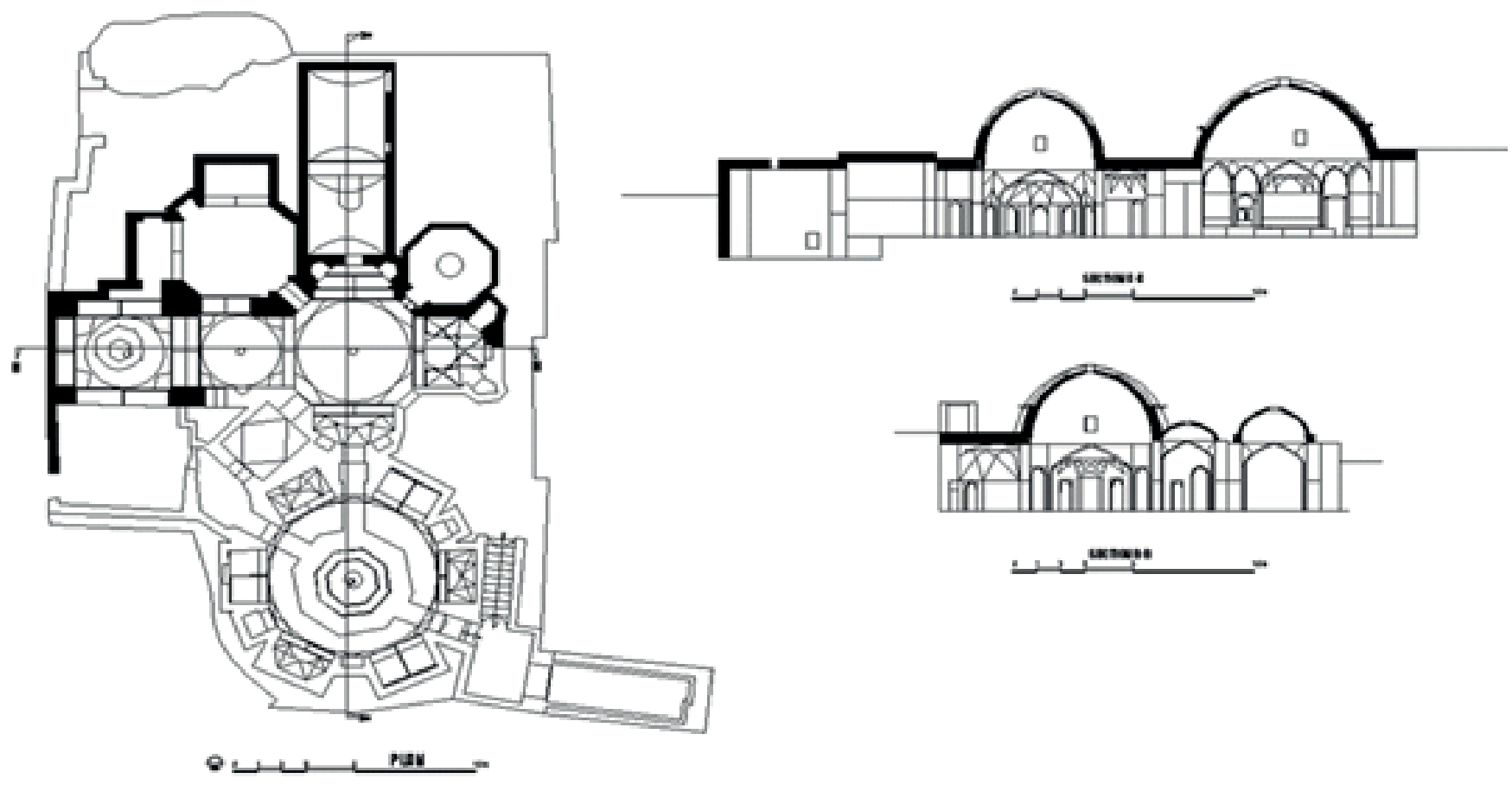

Fig. 7. The cut façade A-A and B-B of the Bath Market (Ganbar Amu Bathroom) (Source: Writers)

6.5 The investigation of the decorations and the interior architecture of the (Ganbar Amu Bathroom)

The decorations of this building have been completely ruined because seen (Fig. 8). The used materials here are the bricks, stones, mortar. The mortar is applied at the foot because of the penetration of the moisture into the upper part.
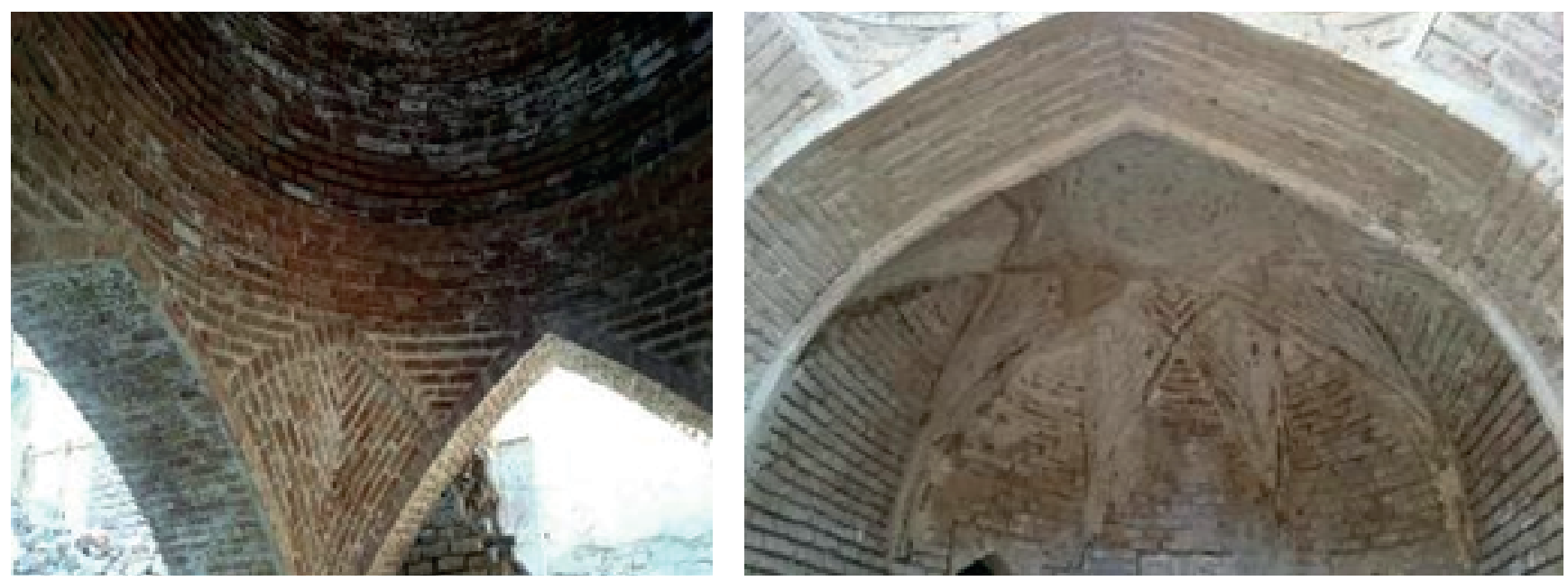

Fig. 8. The ceiling of the Ganbar Amu Bathroom (Source: Writers) 
7. THE PLAN FOR THE RESTORATION OF THE BAZAAR BATHROOM (GANBAR

\section{AMU BATHROOM) IN SHABESTAR AND SUBMITTING A PROPOSAL FOR ITS} REVITALIZATION

The investigating of the damages for this place and submitting the cure for this damages based on (Table 1).

Table 1. Repairing plan and submitting the proposal for the roof of the bathroom (Source: Writers)

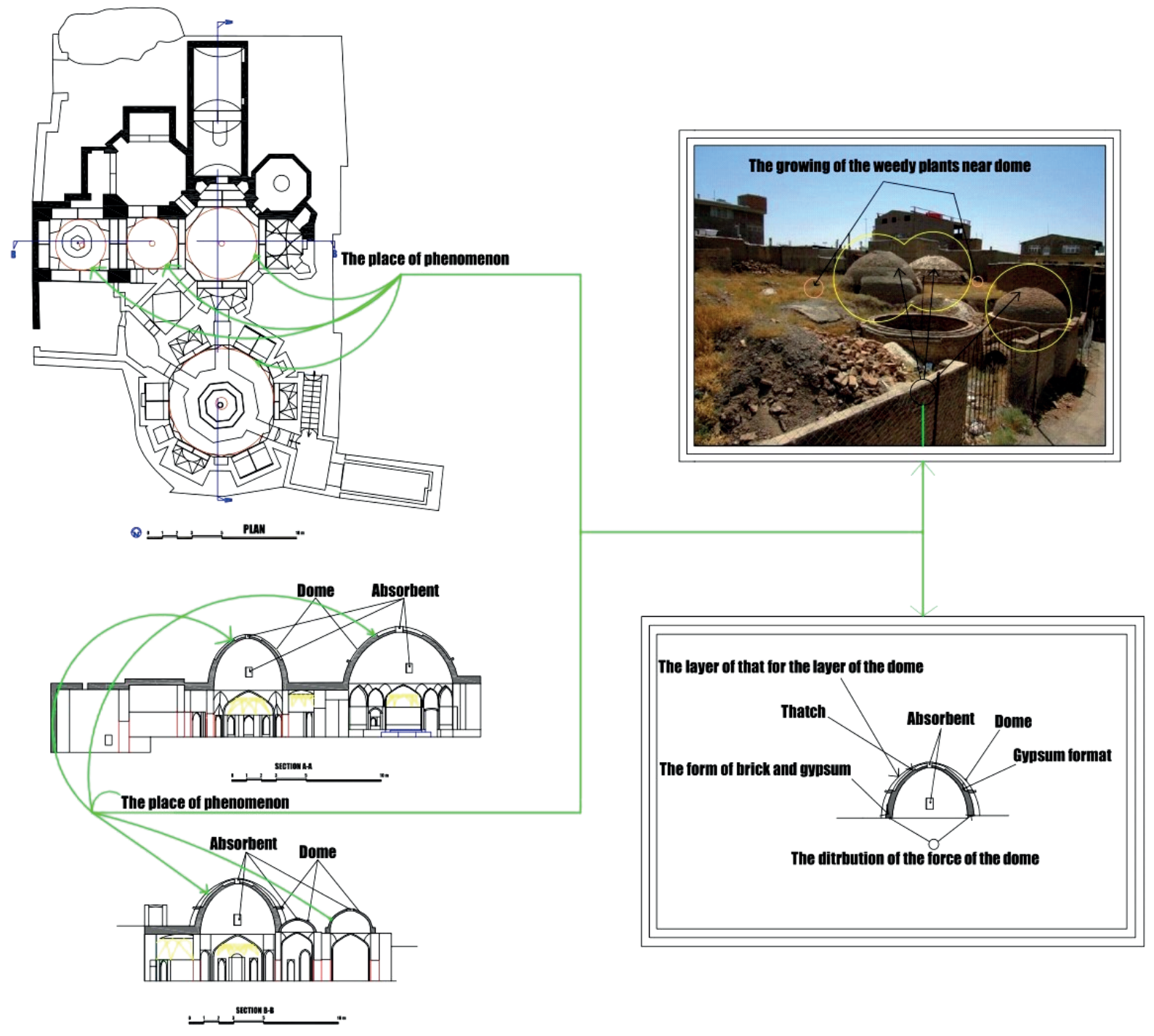

Damage: Natural and Human factors

Disruptive agent

Phenomenon

Cure
The moisture of rain and the penetration of weedy plants.

The destruction of the coverings of the domes.

The restoration of the domes and roof with references to the historical documents and the existing maps and keeping them in the excavation with reference to the conditions of the climate and the other disurptive agents. 
The investigation of the damages to the interior space and presenting the proposal for the cure and its agents based on (Table 2).

Table 2. The refinement plan and the proposal offer in the interior of the bathroom(Source: Writers)
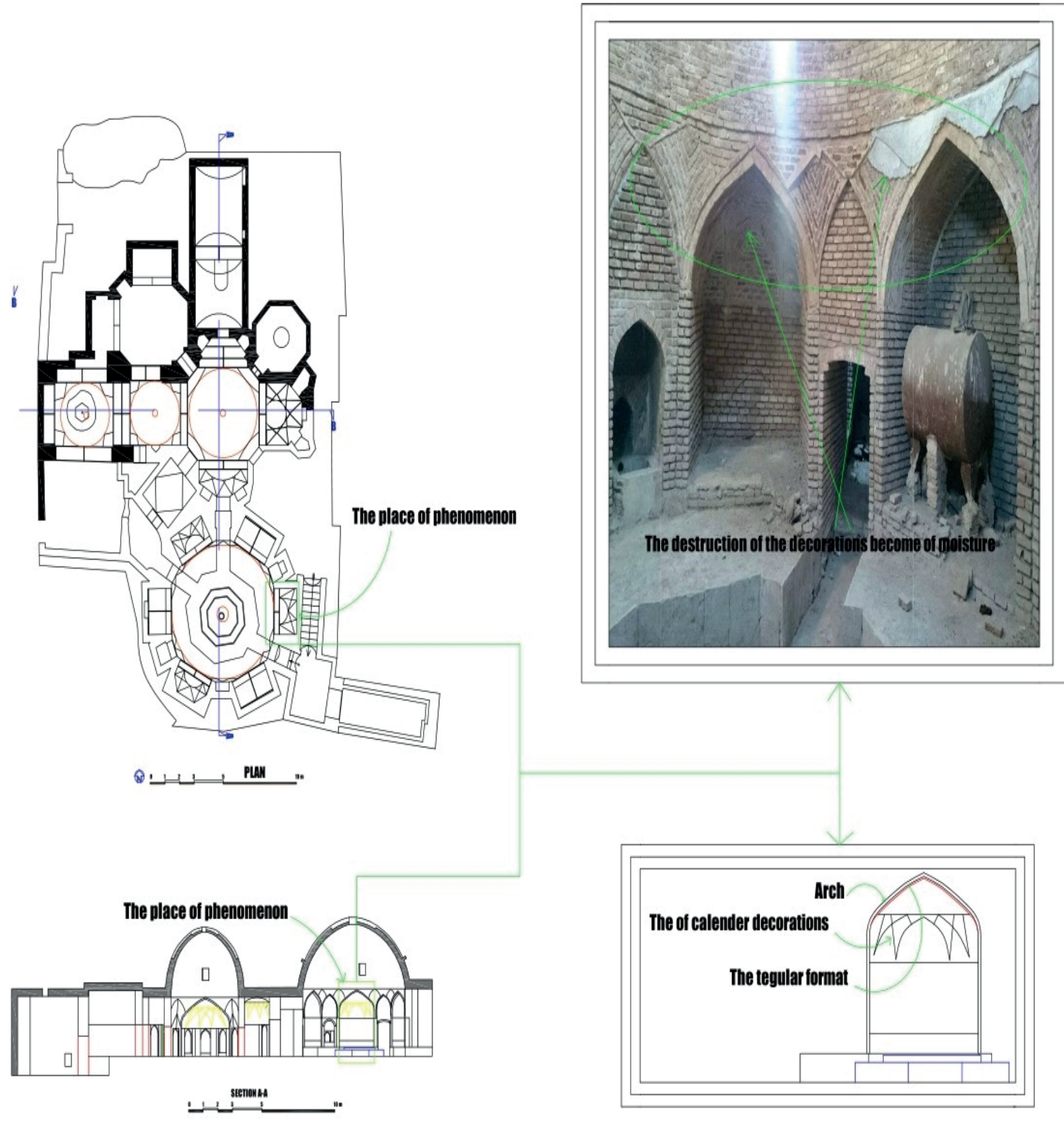

Damage: The natural and human factors

Disruptive Agent

Phenomenon

Cure
Penetration of rain water and atmospheric pecipitations and nonnormative restoration.

The destruction of the part of the decoration.

Insulation and sealage in accordance with the principles and the Iranian achitecture characteristics. 
The investigation of the damages to the interior part of the bathroom and presenting the cure based on the (Table 3).

Table 3. The refinement plan and the offering of the proposal for the interior part of the bathroom (Source: Writers)

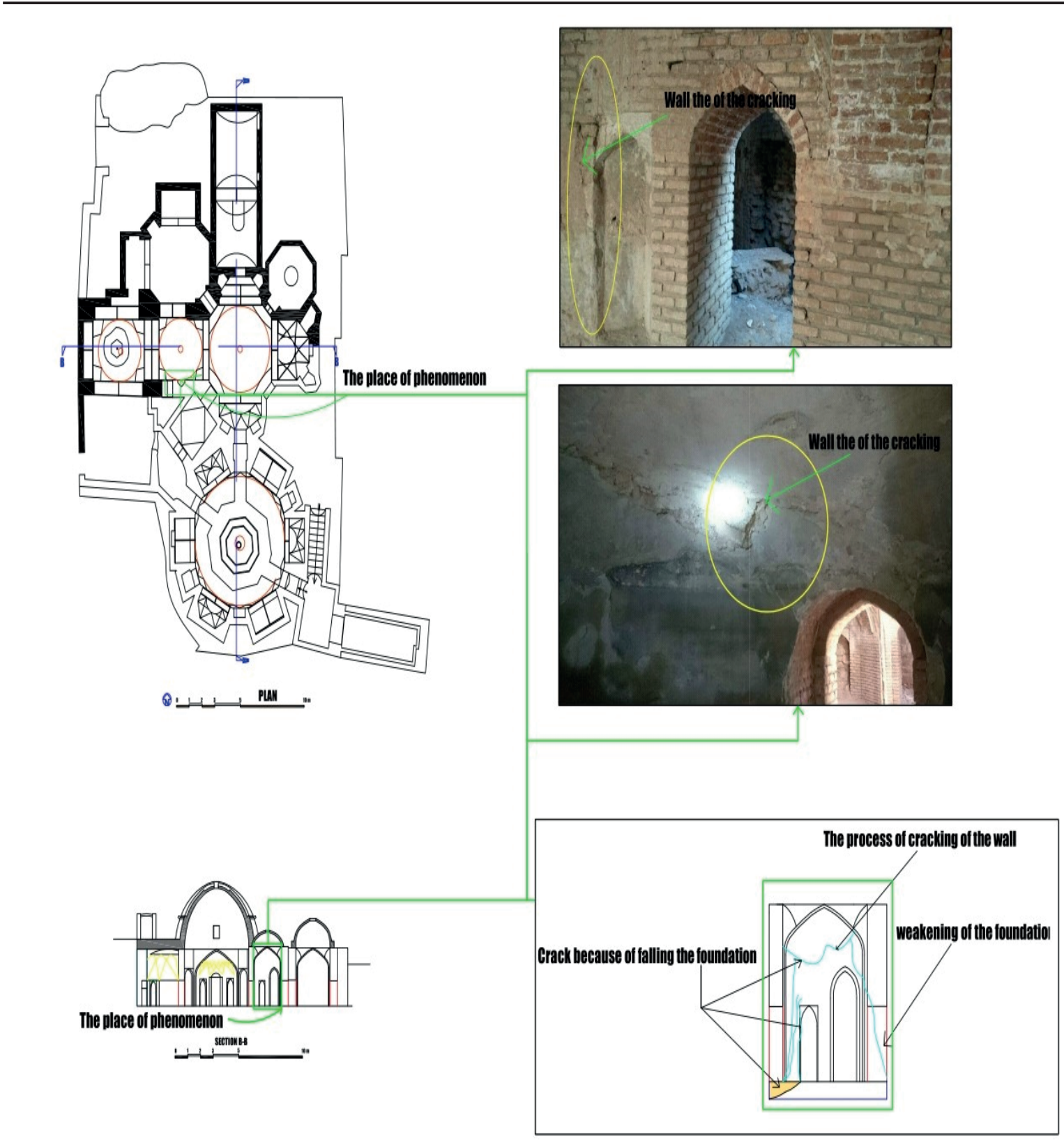

Damage: The natural and Human factors

Distuptive agent

Phenomenon

Cure
Humidity and the infirmity of the foundation.

Cracking of the wll and the disassembly of the bricks.

The strenthening of the foundation with concrete injection to the foot by electorstatic method for moisture removal. 
The investigation of the damages to the interior parts of the bathroom and presenting the proposal for its cure based on (Table 4).

Table 4. The refinement plan and the offering of the proposal for the interior of the bathroom (Source: Writers)

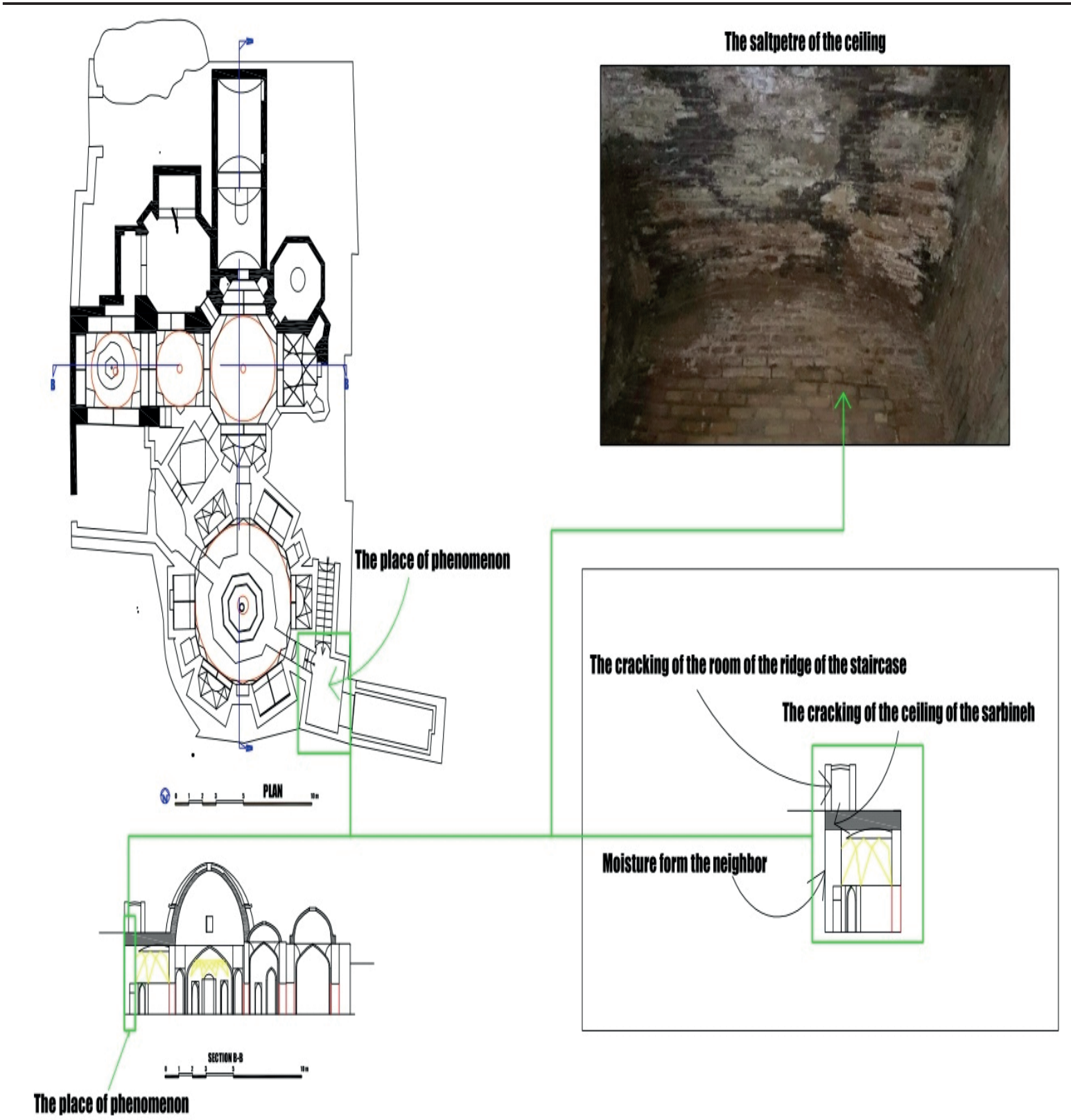

Damage: Natural and Human factors

Disruptive agent

Phenomenon

Cure
Moisture of the neighboring walls and the cracking of the ceiling. The roofdandruff and the changing of the colors of the bricks.

Restoration of the ceiling and repairing of the layers of the Sarbineh and removing moisture and lightening of the roof and suitable slope of the roof 
The investigation of the damages to the interior parts of the bathroom and presenting the proposal for its cure based on (Table 5).

Table 5. The repairing plan and offering the proposal for the interior space of the bathroom (Source:Writers)

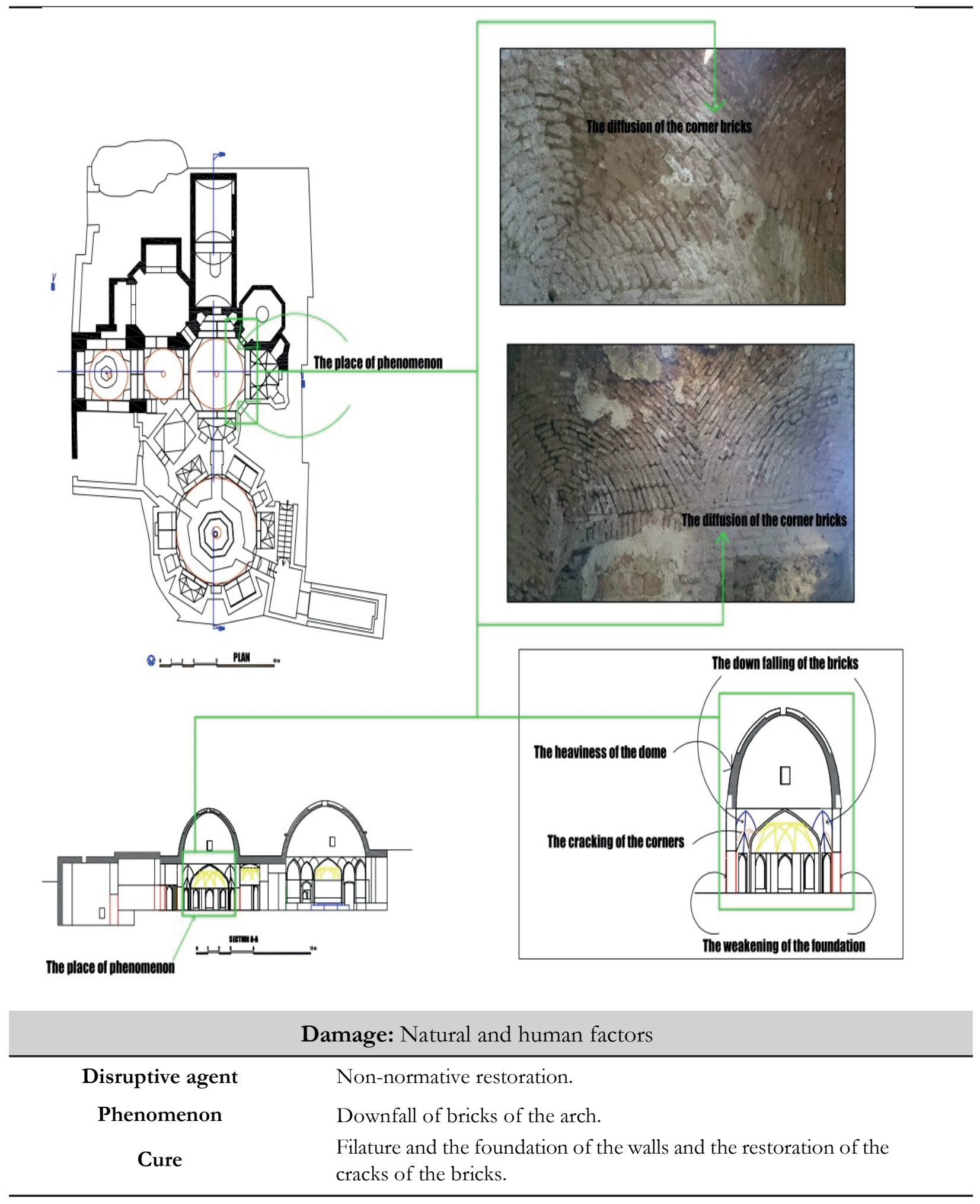




\section{CONCLUSION}

In this study it became clear that in those times the architecture of the Qajar era was important and remarkable in the design and the architecture of the buildings. It can also be said that the bathroom was not only an element of social, cultural, sanitationa but also an element of applied identity. Ganbar Amu bathroom having the characteristics of the Qajar era had also all the Iranian characteristics too. Unfortunately the government has not paid any attention to it and it is now only a ruined place without any value. The main goal of this study is to suggest a repairing plan for it so that its main identity can be saved and it can be used as another place in another application.

\section{REFERENCES}

1. Ghobadian, V. (2003). Climatic survey of traditional Iranian buildings, Tehran University Press.

2. Lotfi, A, a mosque, h. (1392). Farhangvarakoor Garmaba, Published by Aban.

3. Allameh majlesi, M. (2005). "Halie Muttaqin", Publication of the Holy Mosque of Jamkaran.

4. Fakhar'Tehrani, F. (2000). Bathroom, "Architecture of Iran: The Islamic Period", By Mohammad Yousef Kiani, Side Publishing.

5. Pirnia, M. (1999). "Introduction to Islamic architecture" Buildings Inner city and outskirts", ed Gholam Hossein Memarian, Publication of Iran University of Science and Technology.

6. Blokabashi, AS. (1995). How to shape Graceful coffee architecture House, Proceedings of the First Congress of Architectural and Urban History of Iran, Publishing House of Heritage of the Country.

7. Tabassi, M. (2002). Reflection of endowment and physical examination of Aligholi Agha neighborhood center, Quarterly Journal of Sufeh, Volume 12, Issue 35. 